\title{
MENSURAÇÃO DA INOVAÇÃO EM EMPRESAS DE BASE TECNOLÓGICA
}

\section{Helton Cristian De Paula}

Doutor em Administração pela Universidade Federal de Minas Gerais - UFMG

Professor da Universidade Federal de Ouro Preto - UFOP

heltoncristian@gmail.com (Brasil)

\section{Debora Borlido Starling}

Graduanda em Engenharia de Produção da Universidade Federal de Minas Gerais - UFMG

deborabstarling@gmail.com (Brasil)

\section{Juliana Fontes Nascimento}

Graduanda em Engenharia de Produção pela Universidade Federal de Minas Gerais - UFMG juliana@gmail.com (Brasil)

\section{Francisco Vidal Barbosa}

Doutor em Competitividade Empresarial pela Aston University, Inglaterra

Professor Associado da Universidade Federal de Minas Gerais - UFMG

fvberlim@gmail.com (Brasil)

\section{RESUMO}

A inovação tem sido utilizada por um número cada vez maior de empresas como estratégia para obter vantagem competitiva. Para potencializar o desenvolvimento da inovação, vários governos têm incentivado o desenvolvimento de incubadoras de empresas. Dentre os tipos de incubadoras de empresas, destacam-se no contexto da inovação as de base tecnológica, que são aquelas que abrigam empresas com grande potencial de inovação. Apesar da importância da inovação no contexto atual, em especial para as empresas vinculadas a incubadoras de base tecnológica, não foi encontrado consenso na literatura especializada quanto a um conjunto de indicadores que possibilitem monitorar o processo de inovação. Face ao exposto, o presente trabalho se propõe a analisar os mecanismos utilizados para mensurar a inovação tecnológica e propor um conjunto de indicadores para monitorar esse processo nos empreendimentos de base tecnológica. Para isso, foi realizado um estudo exploratório das incubadoras associadas à Rede Mineira de Inovação (RMI) e de suas empresas incubadas, por meio de questionários estruturados e entrevistas semiestruturadas, respectivamente. A pesquisa investigou o uso de mecanismos para mensurar a inovação nesses empreendimentos e constatou o desconhecimento do assunto pela maioria dos participantes. A partir dos problemas e necessidades apontados e da literatura sobre o tema, foi proposto um conjunto de indicadores para mensurar a inovação nessas empresas.

Palavras-chave: Incubadoras de Empresas; Empresas de Base Tecnológica; Indicadores de Inovação. 


\section{INTRODUÇÃO}

A obtenção de vantagem competitiva pelas organizações a partir do desenvolvimento de práticas inovadoras é uma estratégia cada vez mais comum no mundo corporativo. Diante deste fato, é imprescindível o desenvolvimento de novas práticas de gestão que impulsionem melhorias em produtos e processos, transformando-as em um diferencial competitivo. Bessant e Tidd (2009) afirmam que a inovação é uma questão de sobrevivência para as empresas, devido à alta competitividade presente no ambiente empresarial.

Para potencializar o desenvolvimento da inovação, vários governos têm incentivado a o desenvolvimento de incubadoras de empresas. Esse tipo de estratégia de fomento de empresas inovadoras tem apresentado um crescimento acelerado, o que ilustra a sua importância.

Apesar do suporte dado pelas incubadoras, as empresas nascentes sofrem de uma alta taxa de mortalidade. Em estudo realizado em Minas Gerais, determinou-se uma taxa de mortalidade da ordem de 50\% no segundo ano de vida (SEBRAE-MG, 1997, apud Machado et. al., 2001). Isso porque existem várias barreiras que as empresas devem enfrentar para se consolidar no mercado, sendo uma das principais relacionadas a financiamento. Além disso, as Empresas de Base Tecnológica (EBTs) possuem um caráter inovador e tecnológico, que as diferenciam das demais. Esse fator é de extrema importância para o sucesso dessas empresas e deve ser parte essencial na avaliação realizada pelas incubadoras.

Através de pesquisa bibliográfica realizada na literatura especializada, não foi encontrado um consenso sobre indicadores para avaliar o processo de inovação das EBTs. O que se observa é o acompanhamento do desenvolvimento das empresas de uma maneira informal ou por meio da utilização de indicadores de desempenho tradicionais, não considerando o seu caráter tecnológico. Nesse sentido, os indicadores de desempenho que deveriam servir como uma ferramenta capaz de auxiliar no processo de gestão da empresa e também para direcionar os esforços de suporte da incubadora não atendem à sua função. Várias pesquisas apontam a importância de mecanismos de mensuração (Harrington, 1991, Sink e Tuttle, 1993, Matesco, 1993, Hronec, 1994, Batocchio e Yongquan, 1996, Kuczmarski, 1998, Andreassi, 1999 e Viotti, 2003), e algumas delas (Matesco, 1993, Andreassi, 1999 e Viotti, 2003) destacam a inexistência de um modelo consensual para tal, o que denota uma possibilidade de investigação sobre os mecanismos já empregados, e, principalmente, a proposição de um modelo que busque um direcionamento na execução desta tarefa.

Revista de Administração e Inovação, São Paulo, v. 12, n.4 p. 232-253, out./dez. 2015. 


\section{REFERENCIAL TEÓRICO}

\subsection{Empresas de base tecnológica}

A delimitação do conceito de EBTs não é uma tarefa fácil uma vez que se trata de um tema relativamente recente e multidisciplinar. De acordo com o Regulamento 49/91 Art. $2^{\circ}$, b. do Banco Nacional de Desenvolvimento Econômico e Social Participações S/A (BNDES-PAR) citado por Baêta (1999): “A empresa de base tecnológica é aquela que fundamenta sua atividade produtiva no desenvolvimento de novos produtos ou processos, baseados na aplicação sistemática de conhecimentos científicos e tecnológicos e na utilização de técnicas consideradas avançadas ou pioneiras”. Já a Financiadora de Estudos e Projetos - FINEP (2013) define estes empreendimentos como sendo aqueles que possuem na inovação tecnológica os fundamentos de suas estratégias competitivas.

Segundo Baêta (1999), nas EBTs, a tecnologia é o diferencial de competitividade, isto é, a inovação tecnológica é a razão da maior parte dos custos da empresa, e é em tecnologia que a maioria do pessoal trabalha. Dessa forma, a informação e o conhecimento tecnocientífico são essenciais para o sucesso da empresa no mercado e, por isso, esta deve contar com pesquisadores de alta qualificação e investimento em pesquisa e desenvolvimento.

Porém, é necessário diferenciar as EBTs já existentes e consolidadas, com aquelas em processo de criação. Miranda (2003) e FINEP (2013) destacam que as empresas nascentes de base tecnológica são aquelas normalmente geradas em instituições de pesquisa e desenvolvimento e que possuem como característica principal, além do pouco tempo de existência, um tamanho reduzido. Essas empresas, por estarem no início de suas atividades, enfrentam dificuldades relacionadas à infraestrutura e consolidação. Segundo Baêta (1999), os problemas vão desde a escassez de recursos financeiros até dificuldades de alocação de produtos no mercado, refletindo em uma gama de obstáculos a serem superados.

\subsection{Incubadoras de empresas de base tecnológica}

As incubadoras são definidas como um espaço físico com infraestrutura técnica e operacional configurado para acolher micro e pequenas empresas nascentes, bem como aquelas que buscam a modernização de suas atividades, de forma a transformar ideias em produtos, processos e/ou serviços (ANPROTEC, 2003). Em uma visão mais específica, Baêta (1999) afirma que incubadoras de empresas de base tecnológica (IEBTs) são organizações que abrigam empreendimentos nascentes cujo

Revista de Administração e Inovação, São Paulo, v. 12, n.4 p. 232-253, out./dez. 2015. 
Mensuração da inovação em empresas de base tecnológica

projeto implica inovações e que as incubadoras são pontos chave para a interação Universidade/Empresa.

A primeira incubadora criada em Minas Gerais, segundo dados da Rede Mineira de Inovação (RMI), foi a do Instituto Nacional de Telecomunicações (Inatel), localizada em Santa Rita do Sapucaí, em 1992 (Arantes, 2013). Atualmente a RMI conta com 23 incubadoras associadas.

\subsection{Conceitos associados à inovação}

O conceito de inovação ainda hoje não é consenso no meio acadêmico. Schumpeter (1982) define inovação como um processo marcado pela descontinuidade do que já está estabelecido e concebido por meio da introdução de um novo bem ou nova qualidade de um bem, de um novo método de produção, da abertura de um novo mercado, da conquista de uma nova fonte de matériaprima ou, até mesmo, da criação de uma nova forma de organização.

Tushman e Nadler (1986) definem a inovação como sendo a criação de algum produto, serviço ou processo que é novo para a unidade de negócio. Eles distinguem dois tipos de inovação: (1) de produto e (2) de processo. Segundo o Manual de Oslo (2004), inovação de produto é a implantação de um produto com características de desempenho novas e/ou aprimoradas. Já a de processo, é definida como a implantação de métodos de produção ou comercialização novos ou aprimorados. Além destas duas classificações, é comum encontrarmos na literatura a caracterização da inovação em três classes

(Freeman, 1974; Henderson \& Clark, 1990; e Christensen, 1997): (1) Incrementais, aquelas que propõem um incremento a um produto, processo ou serviço já existente; (2) Radicais, aquelas que criam produtos, processos ou serviços novos e (3) Disruptivas, aquelas que rompem completamente com as formas de produção e organização anteriores ao processo de inovação.

\subsection{Indicadores de inovação}

Os indicadores apresentam-se como uma forma de medição necessária para o estabelecimento de metas e o controle dos resultados de desempenho de uma organização (Takashina \& Flores, 1996 Apud Pinto, 2004), auxiliando na tomada de decisão e no processo de melhoria contínua. Segundo Kolk et. al. (2012), empresas que implementam indicadores de desempenho voltados para a inovação aumentam sua produtividade de 20 a 50\%. Além disso, segundo esses autores, ao elaborar tais

Revista de Administração e Inovação, São Paulo, v. 12, n.4 p. 232-253, out./dez. 2015. 
indicadores é preciso levar em consideração os objetivos principais da inovação: retorno financeiro, vantagem competitiva e desenvolvimento de recursos humanos.

Apesar da sua importância, a mensuração do processo de inovação tecnológica não é uma tarefa fácil. Segundo Matesco (1993, apud Pinto, 2004), "não há consenso sobre quais variáveis devam ser incluídas para explicar o esforço inovador...". A inovação, por ser uma novidade, não apresenta semelhanças claras entre seus atributos passíveis de serem comparados de forma quantitativa.

Os primeiros indicadores da atividade de inovação tiveram como base o Modelo Linear de Inovação, segundo o qual a inovação segue sempre um fluxo linear e contínuo, desde a pesquisa básica até a comercialização do produto. Como consequência, tais indicadores adotam como foco inputs e outputs da atividade de inovação (Arundel et. al., 1998, apud Pinto, 2004) e representam os indicadores tradicionais da inovação. Como exemplos, têm-se aqueles relacionados aos gastos com P\&D, grau de qualificação de recursos humanos e patentes. Já o Instituto Euvaldo Lodi (2007) divide os indicadores de inovação em indicadores de entrada, de processo e de saída. Os indicadores de entrada revelam o esforço empreendido para inovar. Os de processo possibilitam o acompanhamento da evolução no desenvolvimento dos projetos inovadores. Já os indicadores de saída mensuram os resultados da implantação da inovação para o negócio da empresa.

Milbergs e Vonorta (2004, apud Emrich, 2012) classificam os indicadores tradicionais em relação a quatro diferentes gerações. Os indicadores de primeira geração (1950-1960) são focados em inputs que envolvem: investimento em $\mathrm{P} \& \mathrm{D}$, aplicação de capital, pessoas alocadas em pesquisa e intensidade tecnológica. Como exemplos de indicadores de segunda geração (1970-1980) são citados aqueles relacionados com as características dos produtos, melhorias de qualidade, publicações científicas e patentes, ou seja, indicadores de output. Na terceira geração (1990) são utilizados indicadores de processamento de informação que interligam os dados de input e output como: surveys, indexação, capacidade inovativa, benchmarking. Por último, na quarta geração (2000) os indicadores são fundamentados em todos os princípios das gerações anteriores, além de serem capazes de mensurar um processo inovativo em tempo real e de forma global. Já Cavalcante e De Negri (2013) retratam cinco dimensões nas quais os indicadores são formados. São elas: econômica; setorial; gastos em atividades de inovação; recursos humanos alocados em atividades de inovação; e resultados das atividades de inovação.

Os indicadores tradicionais não são capazes de medir o processo de inovação como um todo, apenas suas entradas e saídas, ou seja, os recursos utilizados e os resultados finais, sem avaliar o decorrer do processo. Como apresentado por Pinto (2004) esses indicadores fornecem apenas uma indicação do esforço utilizado para se obter a inovação.

Revista de Administração e Inovação, São Paulo, v. 12, n.4 p. 232-253, out./dez. 2015. 
Segundo Vantrappen e Metz (1995) os indicadores tradicionais possuem limitações, ao deixar de reconhecer que a inovação é um processo criativo, que não se adéqua a verificações de rotina. Além disso, raramente fornecem padrões específicos para comparar cada fase da cadeia de inovação; normalmente consideram indicadores "atrás", que medem como foi realizado o processo de inovação após o fato e, por isso, não possibilitam prontamente uma ação corretiva; e muitas vezes esses indicadores tendem a ser muito agregados ou com foco restrito em uma função da empresa, como, por exemplo, a engenharia.

Por isso, alguns autores defendem a adoção de novos indicadores, chamados de "inovadores dinâmicos". Esses indicadores englobam seis princípios necessários à sua formulação, segundo Vantrappen e Metz (1995):

- $\quad$ Estabelecer uma parceria entre Negócio e Pesquisa \& Desenvolvimento;

- Ligar os indicadores à estratégia da empresa;

- Utilizar um espectro de indicadores de desempenho;

- Interpretar e ajustar continuamente os indicadores;

- Aprender a partir das medidas de desempenho e agir de acordo com elas;

- Combinar as medições acionadas por calendário com análises acionadas por eventos.

Como exemplos de indicadores dinâmicos, Marins (2010) propõe um conjunto de acordo com quatro dimensões (empreendedorismo, estrutura, coordenação e valor). Esses indicadores, segundo a autora, buscam avaliar o desdobramento do processo de inovação nas empresas.

\section{METODOLOGIA}

Para desenvolvimento deste trabalho foi realizada uma pesquisa qualitativa por meio de questionário com questões abertas com incubadoras associadas à RMI. Essa escolha foi feita em função da localização dos pesquisadores e da representatividade da RMI, que conta com 23 incubadoras e 3 parques tecnológicos associados, os quais respondem por 292 empresas e 5.200 empregos diretos e indiretos (RMI, 2014). A primeira parte dos questionários foi aplicada presencialmente na $3^{\circ}$ Reunião Anual de Associados e Parceiros da RMI nos dias 28 e 29 de novembro de 2013 em Itajubá - Minas Gerais. Para as incubadoras que não participaram da Reunião ou que optaram por não responder durante o evento, foram enviados os mesmos questionários por e-mail. No

Revista de Administração e Inovação, São Paulo, v. 12, n.4 p. 232-253, out./dez. 2015. 
total, foram obtidas respostas de 15 incubadoras associadas e 1 incubadora em processo de formalização, conforme gráfico abaixo:

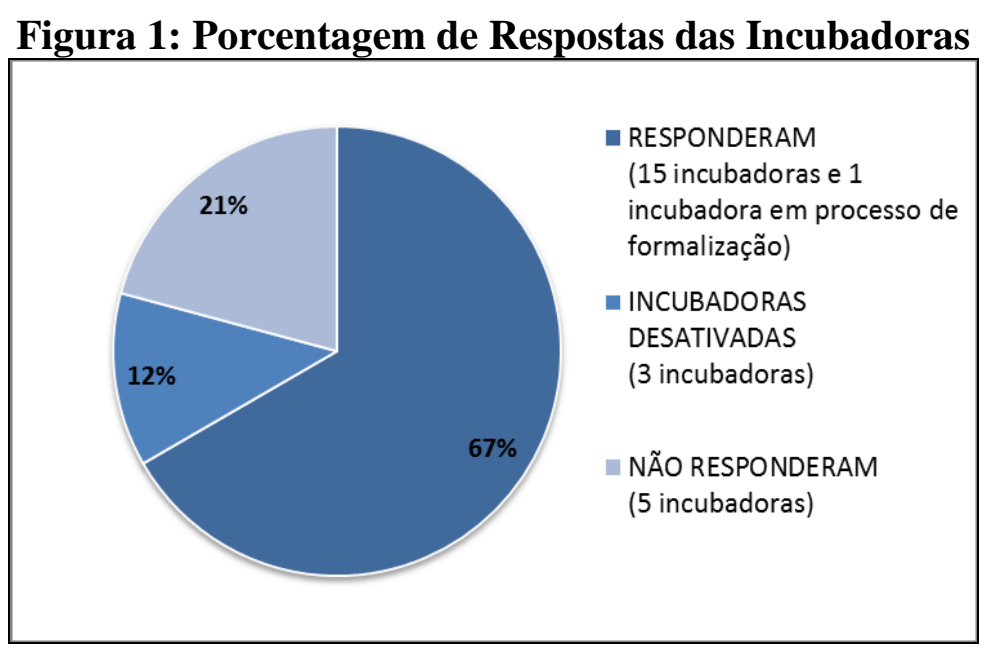

Fonte: Elaborado pelos autores

Na terceira fase de coleta de informações, utilizou-se novamente uma abordagem qualitativa para realizar um estudo multicasos. Foram realizadas entrevistas semiestruturadas com representantes de EBTs que fazem parte de incubadoras associadas à RMI. As entrevistas foram realizadas no período de março e abril de 2014 com duração de 20 a 40 minutos. O roteiro, uma vez elaborado, foi submetido a um pré-teste com duas empresas incubadas a fim de analisar a necessidade de ajustes ou modificações.

Foram entrevistadas 12 empresas de um universo de 115 empresas vinculadas às incubadoras participantes da primeira etapa da pesquisa. Essas empresas foram selecionadas de modo a se obter um mix variado de fases de desenvolvimento, ramo de atuação, tempo de incubação e localização geográfica. Em duas das entrevistas dois sócios participaram e nas outras houve a participação de apenas um representante. Além disso, 8 entrevistas foram realizadas presencialmente e 4 via aplicativo Skype. Desse total de empresas 10 são incubadas e 2 graduadas.

De modo a manter o sigilo e a confidencialidade dos dados dos participantes da pesquisa, foram atribuídos códigos aos respondentes. Os participantes foram separados em três grupos: Incubadoras serão denominadas INC, variando de INC1 a INC16; Empresas de base tecnológica incubadas serão denominadas EBTI, variando de EBTI1 a EBTI10; e as Empresas de base tecnológica graduadas são denominadas EBTG, variando de EBTG1 a EBTG2. As características das empresas entrevistadas são apresentadas no Quadro 1 e, a partir do nível de desenvolvimento de cada EBT, elas foram divididas 
conforme a Figura 2 a fim de fazer uma análise mais aprofundada e entender as diferentes necessidades em diferentes estágios de desenvolvimento.

Quadro 1 - Características das Empresas Estudadas

\begin{tabular}{|c|c|c|c|c|c|}
\hline $\begin{array}{l}\text { Empresa } \\
\text { entrevistada }\end{array}$ & $\begin{array}{c}\text { Pessoa } \\
\text { Entrevistada }\end{array}$ & Ramo de atuação & $\begin{array}{l}\text { Incubadora } \\
\text { vinculada }\end{array}$ & $\begin{array}{l}\text { Tempo de } \\
\text { incubação }\end{array}$ & Cidade \\
\hline EBTI1 & Sócio fundador & Software & INC2 & 4 anos & Uberlândia \\
\hline EBTI2 & Sócio fundador & $\begin{array}{l}\text { Educação / } \\
\text { Software }\end{array}$ & INC2 & 5 meses & Uberlândia \\
\hline EBTI3 & $\begin{array}{c}\text { Sócios } \\
\text { fundadores }\end{array}$ & $\begin{array}{l}\text { Controle e } \\
\text { Automaçãao }\end{array}$ & INC2 & 5 meses & Uberlândia \\
\hline EBTI4 & Sócio fundador & Biotecnologia & INC2 & 8 anos & Uberlândia \\
\hline EBTI5 & $\begin{array}{l}\text { Gerente de } \\
\text { marketing }\end{array}$ & Veterinária & INC5 & 1 ano e 6 meses & Lavras \\
\hline EBTI6 & Sócio fundador & Software & INC11 & 1 ano & Belo Horizonte \\
\hline EBTI7 & Sócio fundador & $\begin{array}{l}\text { Automação } \\
\text { Residencial }\end{array}$ & INC11 & 1 ano e 2 meses & Belo Horizonte \\
\hline EBTI8 & $\begin{array}{l}\text { Sócios } \\
\text { fundadores }\end{array}$ & $\begin{array}{l}\text { Captação de } \\
\text { Imagem }\end{array}$ & INC11 & 4 meses & Belo Horizonte \\
\hline EBTI9 & Sócio fundador & $\begin{array}{l}\text { Software / } \\
\text { Serviços }\end{array}$ & INC11 & 2 anos e 6 meses & Belo Horizonte \\
\hline EBTI10 & Sócio fundador & $\begin{array}{l}\text { Automação } \\
\text { Residencial }\end{array}$ & INC4 & 1 ano e 2 meses & $\begin{array}{c}\text { Santa Rita do } \\
\text { Sapucaí }\end{array}$ \\
\hline EBTG1 & Sócio fundador & Educação & INC16 & Graduada & Uberaba \\
\hline EBTG2 & Sócio fundador & $\begin{array}{l}\text { Tecnologia em } \\
\text { micro-ondas }\end{array}$ & INC16 & Graduada & Uberaba \\
\hline
\end{tabular}

Fonte: Elaborado pelos autores.

Figura 2: Classificação das Empresas Estudadas de Acordo com o Nível de Desenvolvimento

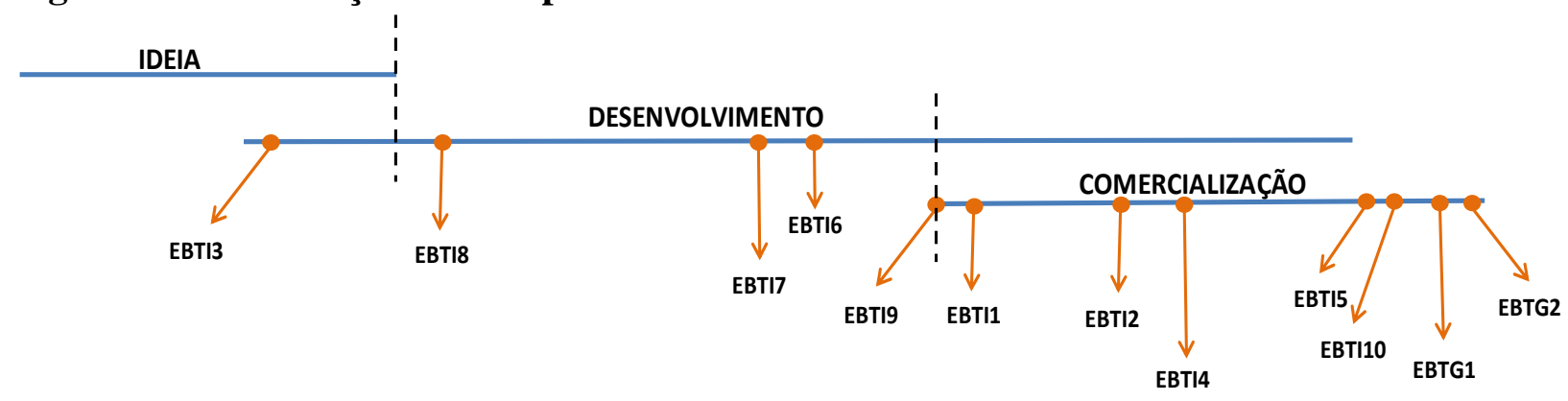

Fonte: Elaborado pelas autores

Nível 1 - Ideia/Início do Desenvolvimento: Empresas ainda não formalizadas que possuem apenas uma ideia ou que estão começando a desenvolver o produto/tecnologia.

Nível 2 - Desenvolvimento: Empresas que já tem o produto/serviço ou processo estruturado e estão em fase de desenvolvimento, porém sem nenhum contato comercial. 
Nível 3 - Desenvolvimento/Comercialização: Empresas que entraram na fase de comercialização e já possuem vendas realizadas ou em processo de realização.

Para compilação e análise das informações obtidas foi utilizada a metodologia de análise de conteúdo. Para a realização da análise de conteúdo, foram utilizadas categorias de análise definidas através da grade aberta.

\section{ANÁLISE DOS DADOS}

\subsection{Análise de conteúdo}

As informações coletadas por meio de entrevistas e questionários com os representantes das EBTs e das incubadoras estudadas, respectivamente, foram resumidas e organizadas dentro de categorias de análises, possibilitando maior clareza dos dados e favorecendo a análise dos mesmos.

\subsection{Indicadores de inovação}

Quadro 2 - Repertório Interpretativo - Indicadores de Inovação

\begin{tabular}{|c|c|c|}
\hline Categorias de Análise & $\mathbf{N}^{\mathbf{O}}$ & Fragmentos Ilustrativos \\
\hline $\begin{array}{lll}\text { A } & \text { importância } & \text { da } \\
\text { mensuração da inovação } & \end{array}$ & 1 & $\begin{array}{l}\text { "Eu acho que não é tão importante até porque é muito difícil } \\
\text { mensurar, né?" EBTI1 } \\
\text { "Sim! A gente é muito preocupado com isso, saber se a gente tá } \\
\text { direcionado ou não." EBTI2 } \\
\text { "Então, existem alguns estágios que obrigatoriamente têm que } \\
\text { acontecer. E esses estágios, então, muitas vezes, travam o processo } \\
\text { de comercialização e etc. [...] pensando nisso, a gente deveria } \\
\text { talvez criar mecanismos pra conseguirmos compreender todo } \\
\text { esse processo [...]" EBTI4 } \\
\text { "[...] o dinamismo desse ambiente de start up eu não sei se se } \\
\text { adéqua tanto a você ter um roteirozinho tão definido, engessado, } \\
\text { sabe?" EBTI9 } \\
\text { "Eu pra ser bem sincero, eu não sei nem falar se seria bom ou se } \\
\text { seria ruim, porque a gente nunca fez." EBTI9 } \\
\text { "Sim, com certeza. Sem dúvida. Basicamente pelo o que eu te } \\
\text { falei: a inovação é o que mantém à frente no mercado." EBTG1 }\end{array}$ \\
\hline $\begin{array}{l}\text { Indicadores utilizados para } \\
\text { medir a inovação }\end{array}$ & 2 & $\begin{array}{l}\text { "Não, a gente não usa nenhum.” EBTI1 } \\
\text { "Não, a gente não tá utilizando, assim, em particular eu não, né? Às } \\
\text { vezes alguém tá utilizando, mas eu não!” EBTI4 } \\
\text { "Inovação em si não. A gente não usa um indicador. [...]" EBTI6 }\end{array}$ \\
\hline $\begin{array}{l}\text { Práticas gerenciais utilizadas } \\
\text { pelas empresas }\end{array}$ & 3 & $\begin{array}{l}\text { "Com base na análise de mercado observando o que tá } \\
\text { acontecendo, a gente traça a meta pra lançar nossos produtos } \\
\text { [...] Na nossa gestão lá o que a gente tem é meta por período e } \\
\text { faturamento." EBTI1 } \\
\text { "A gente costuma ter uma reunião quinzenal, mas nessa reunião a } \\
\text { gente aborda todos os assuntos da empresa e todo início de ano a } \\
\text { gente faz um planejamento estratégico da empresa. Quais são }\end{array}$ \\
\hline
\end{tabular}

Revista de Administração e Inovação, São Paulo, v. 12, n.4 p. 232-253, out./dez. 2015. 


\begin{tabular}{|c|c|c|}
\hline & & $\begin{array}{l}\text { as atividades, assim, metas financeiras, as metas de clientes pra } \\
\text { aquele ano, de independência [...]" EBTI5 } \\
\text { "Indicador de desempenho eu não sou a pessoa mais adequada } \\
\text { pra falar isso. O (sócio)* que é, mas eu acredito que ele usa sim. } \\
\text { Porque uma das reuniões que a gente teve ele citou alguns } \\
\text { indicadores." EBTI6 } \\
\text { "Hoje, aqui na incubadora tem a cada dois meses a gente passa o } \\
\text { levantamento, faturamento, produtos vendidos, produtos } \\
\text { lançados, e a cada dois meses nos é repassado a pontuação que } \\
\text { a gente teve." EBTI10 } \\
\text { "A gente mantém uma atualização, um upgrade dele (produto), } \\
\text { no mínimo a cada três meses. Então, a gente sempre lança algum } \\
\text { recurso novo, a gente lança conteúdos." EBTG1 }\end{array}$ \\
\hline Sugestão de indicadores & 4 & $\begin{array}{l}\text { "Capacitação, Mercado (conhecimento, captação), gestão, } \\
\text { capital, tecnologia, indicadores desses pontos." INC6 } \\
\text { "Impacto no mercado, Aceitação, Impacto social, Impacto } \\
\text { ambiental." INC7 } \\
\text { "Estágio de desenvolvimento do produto inovador; Captação de } \\
\text { recursos de fomento; Atração de investidores; Propriedade } \\
\text { intelectual (quando aplicável); Implantação de tecnologias de } \\
\text { gestão; Produto ser aceito pelos clientes." INC9 } \\
\text { "Numero de produtos/processos/serviços desenvolvidos durante } \\
\text { o período de incubação. São as empresas que estimulam a } \\
\text { criatividade de seus profissionais visando resultados." INC11 } \\
\text { "Por exemplo: a quantidade de teses de doutorado defendidas. } \\
\text { [...] Assim como o número de publicações, né? [...] a melhora da } \\
\text { condição de vida das pessoas de uma maneira geral, vai ser um } \\
\text { reflexo também." EBTI1 } \\
\text { "[...] tempo do primeiro protótipo até lançamento do produto } \\
\text { no mercado. [...] Até assim, o número de protótipos comerciais. } \\
\text { [...] E, eu acho que o número possível de erros que você vai } \\
\text { encontrar. [...] E, no caso, o número de inovações dentro desses } \\
\text { protótipos também, né, quantos desses foram chegar no } \\
\text { mercado. [...] um payback do tempo que você vai demorar pra ter } \\
\text { o lucro real." EBTI8 }\end{array}$ \\
\hline
\end{tabular}

Nota. *As informações reais foram omitidas para preservar a privacidade dos entrevistados e a confidencialidade dos dados.

Fonte: Elaborado pelos autores

Na primeira categoria é investigada a percepção da importância de se medir o processo de inovação pelos entrevistados. Na categoria 2 e 3 são analisados, respectivamente, os indicadores e práticas gerenciais utilizadas. E, na categoria 4, são investigados os indicadores e formas de monitoramento do processo de inovação, sugeridos pelas empresas e incubadoras.

Na categoria 1 são percebidas duas posições distintas em relação à importância de se mensurar o processo inovativo. Alguns entrevistados acreditam na relevância dos indicadores como forma de direcionar as atividades da empresa, compreender todo o processo de desenvolvimento da inovação e pelo fato de a inovação ser a essência dessas empresas e o que as mantém à frente no mercado, respectivamente citados por EBTI2, EBTI4 e EBTG1. Já EBTI1 e EBTI9 discordam da importância 
dessa mensuração. EBTI1 justifica esse posicionamento por acreditar que essa é uma atividade difícil de ser realizada e, portanto, inviável. Já o entrevistado da EBTI9 acredita que essas formas de monitoramento poderiam engessar o processo de desenvolvimento tecnológico, o que não seria interessante em um ambiente dinâmico de start-up. Esses posicionamentos são relevantes na análise de indicadores aplicados para EBTs, principalmente pelo fato de que o uso inadequado desses indicadores ou a escolha de indicadores que não refletem a estratégia da empresa pode acarretar no engessamento do processo de inovação e dificultar o desenvolvimento da empresa. Além disso, devido à falta de consenso na definição de inovação, o ato de tentar medi-la é algo desafiador e que gera dúvidas com relação a que fatores devem ser utilizados.

A partir da análise dessa categoria é possível perceber que a maioria dos entrevistados acredita na importância da mensuração do processo inovativo e sentem a necessidade de terem mecanismos para isso. Por outro lado, a existência de entrevistados que, mesmo que em sua minoria, não consideram essa atividade relevante é um aspecto interessante para ser aprofundado. Isso porque, a inovação é a essência das EBTs e, por isso, passível de ser monitorada. Além disso, a percepção dessas empresas diverge de diversos estudos na literatura que apontam a importância da utilização de mecanismos de mensuração, tais como: Harrington (1991), Sink e Tuttle (1993), Matesco (1993), Hronec (1994), Batocchio e Yongquan (1996), Kuczmarski (1998), Andreassi (1999) e Viotti (2003).

Analisando a categoria 2, pode-se perceber que nenhuma empresa possui a cultura de usar indicadores de inovação e que, além disso, essa prática gerencial é desconhecida por algumas delas. Os fragmentos ilustrativos apresentados no quadro refletem a resposta de todas as empresas pesquisadas que afirmaram não utilizar indicadores, apesar da maioria delas declararem estarem conscientes da importância da mensuração da inovação. Além disso, a citação da EBTI4 nos mostra que existe um desconhecimento por parte do empreendedor sobre indicadores e a forma como utilizá-los, o que pode influenciar nos resultados obtidos por meio dessa ferramenta.

Apesar disso, grande parte das empresas utilizam alguma outra prática gerencial, como mostra a categoria 3. As práticas mais utilizadas pelos entrevistados relacionam-se com o estabelecimento de metas basicamente comerciais. EBTI1 e EBTI10 utilizam metas para lançamento de produtos, vendas e faturamento. Já a EBTI5 realiza reuniões periódicas na empresa para acompanhar as metas de faturamento, de clientes e de independência em relação à incubadora. A EBTG1, por ser graduada, utiliza uma prática que difere das demais, que consiste na atualização de seus produtos a cada três meses para melhorias ou inserção de novas funcionalidades. A citação da EBTI6 revela um desalinhamento entre os sócios da empresa em relação a uma importante prática de gestão, o uso de indicadores e de mecanismos de monitoramento dos processos. Essas práticas, para um bom resultado, deveriam estar difundidas por toda a empresa e, os indicadores deveriam ser analisados pelos gestores

Revista de Administração e Inovação, São Paulo, v. 12, n.4 p. 232-253, out./dez. 2015. 
em conjunto. $\mathrm{O}$ desconhecimento dessa atividade por um dos empreendedores pode influenciar em gerenciamentos ineficientes ou mesmo resultados negativos para a empresa.

Além disso, é possível perceber pelas citações dos entrevistados que a maioria das incubadoras não direciona suas empresas incubadas em relação às melhores práticas gerenciais que poderiam ser adotadas. Por isso, muitas empresas utilizam essas práticas de maneira mais informal. Apenas a incubadora relacionada à EBTI10 possui um processo estruturado de acompanhamento e controle, por meio de um levantamento dos principais aspectos comerciais de sua empresa incubada (produtos lançados, produtos vendidos, faturamento).

A categoria 4 apresenta as sugestões de indicadores apontadas pelas empresas entrevistadas e pelas incubadoras no questionário aplicado a elas. Percebe-se, inicialmente, que o número de fragmentos advindos de incubadoras é superior ao número de respostas das empresas. Isso porque, devido ao desconhecimento a respeito do conceito de indicadores e do fato de indicadores de inovação, para a maioria das empresas entrevistadas, ser algo muito novo e ainda abstrato, a maioria delas não conseguiu contribuir com essa resposta.

Nas respostas das incubadoras, pode-se constatar que o maior número de sugestões é relacionado ao mercado e produto, com destaque para: aceitação do mercado e número e estágio de desenvolvimento de produtos e processos. A INC7 destaca o fator de impacto ambiental e social da tecnologia, muito relevantes atualmente, entretanto muito amplos e de difícil mensuração. A melhoria de vida das pessoas, ou seja, o fator social, também é citado pela EBTI1. A INC9 destaca fatores financeiros como importantes para a mensuração da inovação, entretanto esses são focados em editais e investidores, ou seja, em uma etapa inicial à etapa de vendas e consolidação. Esses indicadores são relevantes visto a carência financeira apresentada pela maioria das empresas e a importância desses recursos para a sobrevivência e desenvolvimento das EBTs. O fator criatividade dos profissionais foi citado apenas por um dos entrevistados, a INC11.

Entre as respostas das empresas, destacam-se as falas de dois empreendedores com visões diferentes a respeito de como medir a inovação. A empresa EBTI1 apresenta um perfil acadêmico e os indicadores apresentados por ela são relacionados a teses de doutorado e publicações. Esses pontos são importantes para a geração de novas tecnologias, porém não são suficientes para a inovação. De acordo com a definição de Tushman e Nadler (1986), em que inovação é a criação de algum produto, serviço ou processo que seja novo para a unidade de negócio, esses indicadores acadêmicos não seriam suficientes. Vohora et. al. (2004) complementa a visão a respeito do caráter acadêmico que muitos empreendedores de spin-offs acadêmicas possuem. De acordo com ele, os acadêmicos possuem muito 
conhecimento tecnológico, mas não possuem suficiente conhecimento de mercado e financeiro para desenvolvimento de sua tecnologia.

Já a EBTI8 colabora com uma visão mais comercial e de desenvolvimento do produto, citando dados de protótipos, erros cometidos e dados financeiros. É importante ressaltar que a empresa EBTI8 é a única empresa que possui conhecimento prévio em indicadores, o que é possível perceber pela forma como as ideias foram apresentadas, com destaque para o caráter quantitativo que elas apresentam. Ambas as respostas das empresas EBTI1 e EBTI8 são importantes para o processo de inovação e complementares umas às outras.

A fim de orientar a pesquisa de indicadores de inovação, também foram investigadas as maiores dificuldades enfrentadas por EBTs em seu desenvolvimento e consolidação no mercado. Os dados obtidos são apresentados abaixo:

Quadro 3 - Repertório Interpretativo - Dificuldades Enfrentadas pelas EBTs

\begin{tabular}{|l|l|l|}
\hline Categorias de Análise & $\mathbf{N}^{\mathbf{0}}$ & Fragmentos Ilustrativos \\
\hline $\begin{array}{l}\text { Dificuldades enfrentadas } \\
\text { no desenvolvimento das } \\
\text { empresas }\end{array}$ & 1 & $\begin{array}{l}\text { "[...] por ser uma área um pouco mais complexa, não tem } \\
\text { muito profissional nessa área [...] A mão de obra que tem hoje } \\
\text { tá empregada ou a gente tá formando." EBTI1 } \\
\text { "Então é, eu acredito que falta ainda é uma visão mais } \\
\text { comercial, porque a gente ta recebendo uma visão } \\
\text { empreendedora ao longo do tempo, mas a visão comercial a } \\
\text { gente não tem." EBTI8 } \\
\text { "[...] no nosso caso, a gente tem uma fase absurdamente grande } \\
\text { que gasta um tempo imenso de pesquisa e desenvolvimento } \\
\text { mesmo, principalmente no desenvolvimento do produto." EBTI9 } \\
\text { "Start up ta o tempo inteiro mudando, você não sabe } \\
\text { exatamente como você vai ta [...] daqui dois meses, daqui uma } \\
\text { semana já pode mudar algumas coisas." EBTI9 } \\
\text { "[...] até se tornar referência existe uma grande resistência. Tem } \\
\text { que quebrar muita barreira pra conseguir chegar no } \\
\text { mercado." EBTG1 } \\
\text { "Esse tipo de inovação de ruptura, ela é de difícil entrada no } \\
\text { mercado." EBTG2 }\end{array}$ \\
\\
\end{tabular}

Fonte: Elaborado pelos autores

A principal dificuldade apontada pela EBTI1 refere-se à escassez de profissionais especializados, por se tratar de um setor tecnológico e da grande demanda por esses profissionais. Por isso, segundo o entrevistado, a empresa precisa formar essa mão de obra para suprir sua necessidade. Já a primeira citação de EBTI9 aborda uma dificuldade compartilhada por diversas EBTs, referente ao 
Mensuração da inovação em empresas de base tecnológica

tempo elevado gasto com P\&D para o desenvolvimento do produto. Essa característica envolve gastos financeiros, necessidade de mobilização de mão de obra e alonga o processo de inovação como um todo. Segundo Machado et. al. (2001), as EBTs estão sujeitas a insucessos ligados à tecnologia e, esse tempo elevado de P\&D faz com que o risco associado a elas seja ainda maior. A EBTI9 também apresenta dificuldades para planejamento em longo prazo, devido ao dinamismo do ambiente ao qual estão inseridos e ao tempo elevado de P\&D citado anteriormente.

As empresas EBTI8, EBTG1 e EBTG2 relatam dificuldades comerciais. A primeira acredita que falta uma visão comercial dos empreendedores para concretizar a ideia em desenvolvimento. Já as empresas graduadas, EBTG1 e EBTG2, apresentam dificuldades de acesso inicial ao mercado. Para EBTG2, o caráter radical de sua inovação é a essência dessa dificuldade. Essa realidade das EBTs, marcadas por pouca experiência em gestão, frágil estrutura de comercialização e quase nenhuma visibilidade no mercado é citada em ANPROTEC (2003). Os autores Vohora, Wright \& Lockett (2004) também relacionam essas dificuldades à falta de conhecimento sobre mercado pelos empreendedores, falta de conhecimento da melhor aplicação da tecnologia e incapacidade de definir um caminho para o mercado e obter consumidores. Assim, é possível perceber, a partir das citações presentes nessa categoria, que as dificuldades enfrentadas pelas EBTs pesquisadas incluem diversos aspectos, o que comprova os variados desafios na implementação e consolidação da empresa.

\subsection{Modelo de indicadores de inovação}

A partir da análise das dificuldades e pontos críticos para competitividade das EBTs brasileiras, realizada no tópico anterior, e contrastando os indicadores presentes na literatura estudada com aqueles sugeridos pelas empresas e incubadoras nessa pesquisa, foi sugerido um conjunto de indicadores de inovação. Como as EBTs apresentam necessidades e dificuldades que divergem umas das outras, esses indicadores foram sugeridos de acordo com os diferentes níveis de desenvolvimento da empresa.

\section{Quadro 4 - Modelo de Indicadores de Inovação}

\begin{tabular}{|l|l|c|}
\hline Indicadores de Inovação & Níveis Aplicáveis \\
\hline Categorias & Sugestão de indicadores & $\begin{array}{c}\text { Ideia, Desenvolvimento e } \\
\text { Comercialização }\end{array}$ \\
$\begin{array}{c}\text { Alinhamento } \\
\text { Mercadológico }\end{array}$ & $\begin{array}{l}\text { Pesquisas de mercado realizadas } \\
\text { empreendedores com clientes, concorrentes e e }\end{array}$ & $\begin{array}{c}\text { Ideia, Desenvolvimento e } \\
\text { Comercialização }\end{array}$ \\
\cline { 2 - 3 } & $\begin{array}{l}\text { Capacidade de acompanhar tendências tecnológicas e } \\
\text { mercadológicas }\end{array}$ & $\begin{array}{c}\text { Ideia, Desenvolvimento e } \\
\text { Comercialização }\end{array}$ \\
\hline
\end{tabular}

Revista de Administração e Inovação, São Paulo, v. 12, n.4 p. 232-253, out./dez. 2015. 


\begin{tabular}{|c|c|c|}
\hline & Feedbacks positivos de clientes & Comercialização \\
\hline \multirow{5}{*}{$\begin{array}{c}\text { Gestão e } \\
\text { Planejamento }\end{array}$} & Alinhamento das ações com a estratégia da empresa & $\begin{array}{l}\text { Ideia, Desenvolvimento e } \\
\text { Comercialização }\end{array}$ \\
\hline & Taxa de extrapolação de orçamento de projetos & Desenvolvimento \\
\hline & Taxa de atraso no cronograma de projetos & Desenvolvimento \\
\hline & $\begin{array}{l}\text { Intervalo de tempo médio entre a concepção de uma ideia } \\
\text { de um novo produto e a disponibilização desse novo } \\
\text { produto no mercado }\end{array}$ & $\begin{array}{l}\text { Desenvolvimento e } \\
\text { Comercialização }\end{array}$ \\
\hline & $\begin{array}{l}\text { Intervalo de tempo médio entre a concepção da ideia de um } \\
\text { novo produto e a aferição de lucros advindos desse novo } \\
\text { produto }\end{array}$ & $\begin{array}{l}\text { Desenvolvimento e } \\
\text { Comercialização }\end{array}$ \\
\hline \multirow{3}{*}{$\begin{array}{c}\text { Potencial para } \\
\text { Desenvolvimento da } \\
\text { Empresa }\end{array}$} & Interatividade & $\begin{array}{l}\text { Ideia, Desenvolvimento e } \\
\text { Comercialização }\end{array}$ \\
\hline & Acesso a recursos, equipamentos e materiais & $\begin{array}{c}\text { Desenvolvimento e } \\
\text { Comercialização }\end{array}$ \\
\hline & $\begin{array}{llll}\begin{array}{l}\text { Parcerias estratégicas } \\
\text { estabelecidas }\end{array} & \text { quantidades de parcerias } \\
\end{array}$ & $\begin{array}{l}\text { Ideia, Desenvolvimento e } \\
\text { Comercialização }\end{array}$ \\
\hline \multirow{6}{*}{ Produto e Tecnologia } & $\begin{array}{l}\text { Número de ideias geradas convertidos em projetos de } \\
\text { inovação }\end{array}$ & Ideia e Desenvolvimento \\
\hline & $\begin{array}{l}\text { Número de projetos de inovação convertidos em } \\
\text { produtos/serviços }\end{array}$ & $\begin{array}{l}\text { Desenvolvimento e } \\
\text { Comercialização }\end{array}$ \\
\hline & Número de melhorias/inovações realizadas no produto & $\begin{array}{l}\text { Ideia, Desenvolvimento e } \\
\text { Comercialização }\end{array}$ \\
\hline & $\begin{array}{l}\text { Busca, depósitos de pedidos e concessão de propriedade } \\
\text { intelectual }\end{array}$ & Desenvolvimento \\
\hline & Número de produtos e serviços lançados & Comercialização \\
\hline & $\begin{array}{l}\text { Diferenciais em relação aos produtos que existem no } \\
\text { mercado }\end{array}$ & $\begin{array}{l}\text { Ideia, Desenvolvimento e } \\
\text { Comercialização }\end{array}$ \\
\hline \multirow{3}{*}{ Equipe } & Investimento em capacitação & $\begin{array}{l}\text { Ideia, Desenvolvimento e } \\
\text { Comercialização }\end{array}$ \\
\hline & Grau de qualificação do pessoal & $\begin{array}{l}\text { Ideia, Desenvolvimento e } \\
\text { Comercialização }\end{array}$ \\
\hline & Equipe multidisciplinar & $\begin{array}{l}\text { Ideia, Desenvolvimento e } \\
\text { Comercialização }\end{array}$ \\
\hline \multirow{2}{*}{$\begin{array}{l}\text { Impacto Social e } \\
\text { Ambiental }\end{array}$} & Aplicabilidade na sociedade como solução de problemas & Ideia e Desenvolvimento \\
\hline & Adequação aos quesitos ambientais & Ideia e Desenvolvimento \\
\hline \multirow{5}{*}{ Financeiro } & Participação em editais & Ideia e Desenvolvimento \\
\hline & Contatos realizados com investidores & $\begin{array}{l}\text { Ideia, Desenvolvimento e } \\
\text { Comercialização }\end{array}$ \\
\hline & Recursos advindos de investidores & $\begin{array}{l}\text { Ideia, Desenvolvimento e } \\
\text { Comercialização }\end{array}$ \\
\hline & Porcentagem dos dispêndios em P\&D & $\begin{array}{l}\text { Ideia, Desenvolvimento e } \\
\text { Comercialização }\end{array}$ \\
\hline & Lucro operacional inovativo & Comercialização \\
\hline \multirow[b]{2}{*}{ Comercial } & Número de produtos inovadores vendidos & Comercialização \\
\hline & $\begin{array}{l}\begin{array}{l}\text { Número de novos colaboradores/stakeholders } \\
\text { estabelecidos }\end{array} \\
\end{array}$ & Comercialização \\
\hline
\end{tabular}

Fonte: Elaborado pelos autores 
Na categoria de "Alinhamento Mercadológico", os indicadores sugeridos têm como objetivo avaliar se a empresa acompanha as tendências de mercado e as necessidades dos clientes como forma de aumentar as chances de aceitação e sucesso do produto ou serviço final. Os três primeiros indicadores propostos podem ser utilizados em todos os níveis de desenvolvimento e correspondem a (1) Pesquisas de Mercado realizadas (2) Benchmarking com clientes, concorrentes e empreendedores e (3) Capacidade de acompanhar tendências tecnológicas e mercadológicas. Esse último pode ser medido a partir da participação em eventos, acompanhamento de revistas especializadas e publicações da área de atuação da empresa. Já o indicador (4) Feedbacks positivos de clientes é um indicador de resultado que visa avaliar a aceitação dos consumidores e deve ser utilizado na fase de comercialização. Os indicadores (1) e (2) são citados na literatura por Milbergs e Vonorta (2004, apud Emrich, 2012). Já o indicador (4) é sugerido pela INC9 no tópico anterior. Esses indicadores foram propostos também com base em algumas dificuldades enfrentadas pelas EBTs estudadas, tais como: a falta de uma visão mais comercial; a dificuldade de alcançar o mercado; o abismo existente entre academia e mercado; o tempo elevado gasto com atividade de P\&D e o dinamismo de startup.

A próxima categoria, "Gestão e Planejamento", engloba indicadores que visam avaliar a adequação das atividades das empresas em relação ao planejado por elas. Os três primeiros indicadores referem-se a: (1) Alinhamento das ações com a estratégia da empresa, (2) Taxa de extrapolação de orçamento de projetos (INSTITUTO EUVALDO LODI, 2007) e (3) Taxa de atraso no cronograma de projetos (INSTITUTO EUVALDO LODI, 2007). A base para o primeiro indicador é a elaboração de um Plano de Negócio estruturado pela empresa e o monitoramento das ações propostas no mesmo. Os riscos advindos do tempo elevado gasto com P\&D e do ambiente dinâmico de startup, citados anteriormente, também podem ser minimizados com o monitoramento do indicador (3), para que o empreendedor não perca a janela de oportunidade devido aos atrasos no cronograma estipulado.

Os dois últimos indicadores dessa categoria estão presentes no trabalho de Marins (2010) e correspondem a: (4) Intervalo de tempo médio entre a concepção de uma ideia de um novo produto e a disponibilização desse novo produto no mercado e (5) Intervalo de tempo médio entre a concepção da ideia de um novo produto e a aferição de lucros advindos desse novo produto. O primeiro busca avaliar o tempo gasto no desenvolvimento da ideia, sendo de grande importância diante de um ambiente em constante mudança. Já o segundo avalia o tempo de payback do produto ou serviço.

A categoria "Potencial para desenvolvimento da empresa" tem por objetivo avaliar os aspectos que, se monitorados, podem alavancar o desenvolvimento da empresa e, em especial, da sua inovação. Três indicadores compõem essa categoria e estão presentes no trabalho de Marins (2010): (1) 
Interatividade, (2) Acesso a recursos, equipamentos e materiais e (3) Parcerias estratégicas. O primeiro indicador visa acompanhar os contatos realizados pelos empreendedores, ou seja, a network. Isso porque problemas como dificuldade em captar investimentos e a necessidade de parcerias foram apontados pelas empresas. O segundo indicador tem como objetivo incentivar as empresas a buscarem recursos, como equipamentos e materiais, que contribuam para o desenvolvimento do seu produto e serviço. Já o terceiro indicador avalia as parcerias estratégicas estabelecidas pelas EBTs, fator essencial visto as diversas necessidades dessas empresas, desde parcerias de compra de materiais até parcerias de vendas.

Na categoria de "Produto e Tecnologia", os indicadores objetivam evolução e a implantação dos projetos no mercado em forma de produtos e/ou serviços, dependendo do nível de desenvolvimento em que a empresa se encontra. Alguns dos indicadores propostos podem ser utilizados durante todas as etapas, como (1) Número de melhorias/inovações realizadas no produto e (2) Diferenciais em relação aos produtos que existem no mercado. O primeiro pode incluir tanto melhorias em produtos já existentes no mercado que as empresas irão começar a desenvolver ou uma atualização do portfólio. Os diferenciais apresentados pelo segundo, podem englobar tanto características novas, melhor adequação às demandas do mercado, serviços complementares ou qualquer melhoria que venha a ser um diferencial em relação aos concorrentes.

Os indicadores (3) Número de ideias geradas convertidas em projetos de inovação e (4) Número de projetos de inovação convertidos em produtos/serviços, procuram controlar as evoluções e a implementação das ideias inovativas. O indicador (5) Busca, depósito de pedidos e concessão de propriedade intelectual é utilizado como um indicador do processo inovativo e devem ser atualizados à medida que o processo evolui. De acordo com Godinho (2009, apud Emrich, 2012), as patentes representam um ponto intermediário entre o desenvolvimento da inovação e a sua exploração econômica. Uma mensuração mais voltada para resultado da inovação é apresentada no indicador (6) Número de produtos e serviços lançados.

Na categoria "Equipe" são sugeridos indicadores para serem avaliados durante todos os níveis de desenvolvimento da inovação por englobarem esforços para capacitação e aprimoramento dos profissionais. Os indicadores são: (1) Investimento em capacitação, (2) Grau de qualificação do pessoal, sugerido por Cavalcante e De Negri (2013) e (3) Equipe multidisciplinar. O grau de qualificação sugerido em (2) engloba não só a formação acadêmica, mas também experiências profissionais anteriores e cursos na área de atuação, por exemplo. Os indicadores dessa categoria visam incentivar as empresas a investirem em capacitação e na presença de equipes com diversas habilidades (gestão, marketing, comercial, financeiro) devido aos problemas apresentados referentes à 
escassez de profissionais especializados, falta de conhecimento e de uma visão comercial dos empresários.

Os indicadores do impacto social e ambiental da inovação estão principalmente relacionados com o bom planejamento e o projeto adequado da tecnologia/produto. O indicador (1) Aplicabilidade na sociedade como solução de problemas visa monitorar se uma demanda de mercado está sendo suprida e se essa tecnologia traz de fato uma melhoria ou uma facilidade para o cliente. Os parâmetros a serem utilizados nesses indicadores podem ser: número de problemas solucionados, grau de facilidade para utilização do produto, aumento da qualidade de vida dos clientes, entre outros vistos como adequados pela empresa. Já o indicador (2) Adequação aos quesitos ambientais engloba fatores de preservação ambiental e adaptação às legislações pertinentes. Sugestões mais detalhadas incluem: redução das embalagens ou que essas sejam mais ecológicas, facilidade do descarte do produto/embalagem, matéria-prima natural ou ecologicamente correta e adequação à legislação ambiental.

Na categoria, "Financeiro", os indicadores propostos podem ser divididos em três tipos: os que visam alcançar uma forma de financiamento, aqueles que medem os retornos financeiros a partir da fase de comercialização e os que medem os gastos em atividades de inovação. Analisando o primeiro tipo temos: (1) Participação em editais, (2) Contatos realizados com investidores e (3) Recursos advindos de investidores. O monitoramento desses indicadores faz com que os esforços das empresas sejam maiores na busca de financiamento o que, trazendo resultados positivos, auxilia no problema de falta de recursos financeiros apresentado por algumas empresas entrevistadas e pode ajudar a diminuir o tempo de desenvolvimento do produto.

Para o segundo tipo é sugerido (4) Lucro operacional inovativo, ou seja, a porcentagem do lucro obtido através da comercialização de produtos inovadores (Instituto Euvaldo Lodi, 2007 e Marins, 2010). Esse indicador é importante principalmente para as empresas que, a fim de obter uma renda inicial, começam sua comercialização com produtos que não possuem inovação para possibilitar o seu desenvolvimento e posterior comercialização daqueles inovadores, ou para empresas mistas que comercializam os dois tipos de produtos. Para o terceiro tipo de indicador financeiro temos (5) Porcentagem dos dispêndios em P\&D, ou seja, dos gastos totais da empresa, qual é a porcentagem que está sendo alocada para desenvolvimento do P\&D da empresa a fim de robustecer a inovação. Esse indicador também é sugerido na literatura por Cavalcante e De Negri (2013).

A última categoria, "Comercial", procura mensurar a comercialização efetiva dos produtos inovadores e inclui os indicadores: (1) Número de produtos inovadores vendidos e (2) Número de 
novos colaboradores/stakeholders estabelecidos. Esses indicadores podem ser utilizados também como uma forma de acompanhamento e constante evolução e manutenção da inovação dentro da empresa, buscando aumentar o portfólio de clientes/parceiros e a venda dos produtos.

\section{CONCLUSÃO}

A partir da pesquisa realizada é possível concluir que a falta de consenso na literatura sobre a definição de inovação acontece também com as empresas incubadas e as incubadoras. A falta de alinhamento quanto a este conceito traz vários desdobramentos de ordem prática, como a dificuldade de se empreender esforços orientados para os mesmos objetivos, uma lacuna entre os serviços ofertados pelas incubadoras e o que as empresas incubadas gostariam de ter acesso, dentre outros.

Com relação aos indicadores de inovação, conclui-se que há desconhecimento por parte das empresas sobre o assunto e que este ainda é um tema que deve ser amplamente discutido e objeto de campanhas de disseminação e orientação entre os atores da inovação. Esse desconhecimento é um fator crítico para o monitoramento do processo e principalmente para o desenvolvimento de ações inovativas.

Os indicadores de inovação propostos nesse trabalho possuem o objetivo de fornecer um norte às EBTS. É importante ressaltar que os indicadores citados para o planejamento dos empreendimentos devem se adequar aos problemas vivenciados pela empresa, e não o contrário. Um conjunto de 30 (trinta) indicadores foi sugerido para que cada empresa possa escolher aqueles que sejam mais adequados as suas necessidades e realidades, evitando assim um engessamento do processo inovativo e um desalinhamento entre os objetivos da empresa e as ferramentas utilizadas. Essa ampla gama de sugestões se justifica pela diferença existente entre as empresas, tanto no sentido de dificuldades enfrentadas e setor de atuação, quanto no nível de desenvolvimento em que elas se encontram.

Como sugestão para pesquisas futuras propõem-se que seja investigado o uso dos indicadores de inovação aqui apresentados em EBTs a fim de validá-los. Além disso, propõem-se a realização de uma pesquisa análoga a desde artigo, porém em âmbito nacional, para afirmar sua validade em outros contextos.

Revista de Administração e Inovação, São Paulo, v. 12, n.4 p. 232-253, out./dez. 2015. 


\section{REFERÊNCIAS}

Andreassi, T. (1991) Estudo das Relações entre Indicadores de P\&D e indicadores de Resultado Empresarial em Empresas Brasileiras. 213 f. Tese de Doutorado em Administração apresentada à Faculdade de Economia, Administração e Contabilidade, Universidade de São Paulo, São Paulo.

Arantes, A. (2013) Diagnóstico das IEBTs mineiras: Análise propositiva, por meio da percepção das empresas graduadas. In: XXIII Seminário Nacional de Parques Tecnológicos e Incubadoras de Empresas, Recife.

ASSOCIAÇÃO NACIONAL DE ENTIDADES PROMOTORAS DE EMPREENDIMENTOS DE TECNOLOGIAS AVANÇADAS - ANPROTEC. Panorama 2003. Retirado de http://www.anprotec.org.br.

Baêta, A. M. C. (1999) O Desafio da Criação. Uma análise das incubadoras de empresas de base tecnológica. $1^{\circ}$ edição. Vozes. 136.

Batocchio, A., \& Yongquan, X. (1996) Considerações sobre medidas de desempenho para sistemas de manufatura de classe mundial. In: Encontro Nacional de Engenharia de Produção, 16, 1996, Piracicaba. Anais. Piracicaba: UNIMEP.

Bessant, J., \& Tidd, J. (2009). Inovação e empreendedorismo. Porto Alegre: Bookman.

Cavalcante, L. R.; De Negri, F. (2013). Índices compostos de inovação: uma proposta de cálculo de ratings para empresas e projetos. Instituto de Pesquisa Econômica Aplicada, n.13. Nota Técnica. Brasília.

Christensen, C. (1997) The Innovator's Dilemma: when new tecnologies cause great firms to fail. Boston: Harvard Bussiness School Press.

Emrich, E. D. (2012) Indicadores de Inovação Tecnológica na Cadeia Produtiva do Tomate. Tese de Doutorado apresentada à Universidade Federal de Lavras, Programa de Pós-Graduação em agronomia/fitotecnia, Lavras.

FINANCIADORA DE ESTUDOS E PROJETOS - FINEP. Recuperado de: http://www.finep.gov.br.

Freeman, C. (1974) The Economics of Industrial Innovation. The MIT Press.

Harrington, J. (1991) Business Process Improvement: the breakthrough strategy for total quality, productivity, and competitiveness. New York: MacGraw-Hill. 274 p.

Henderson, R., \& Clark, K. (1990) Architectural Innovation: the reconfiguration of existing product technologies and the failure of established firms - Technology, Organization, and Innovation. Administrative Science Quarterly, v.35, p. 9-30.

Hronec, S. M. (1994) Sinais Vitais: usando medidas de desempenho da qualidade, tempo e custo para traçar a rota para o futuro de sua empresa. São Paulo: Makron Books. 240 p.

Revista de Administração e Inovação, São Paulo, v. 12, n.4 p. 232-253, out./dez. 2015. 
INSTITUTO EUVALDO LODI. (2007) Metodologia integrada de gestão da inovação: cartilha. Instituto Euvaldo Lodi. Florianópolis, Santa Catarina.

Kolk, M., Kyte, P., Oene, F.V., \& Jacobs, J. (2012). Innovation: measuring it to manage it. Arthur D. Little.

Kuczmarski, T. D. (1998) Por uma Consciência Inovadora. HSM Management, São Paulo, ano 1, n. 6, p. $62-68$, jan./fev.

Machado, S. A. et. al. (2001) MPEs de base tecnológica: conceituação, formas de financiamento e análise de casos brasileiros. São Paulo: SEBRAE. Instituto de Pesquisas Tecnológicas (IPT), 72 p. Relatório Técnico.

MANUAL DE OSLO - OCDE. (2004) Proposta de diretrizes para coleta e interpretação de dados sobre inovação tecnológica. FINEP. (Tradução do original em Inglês proposed guidelines for collecting and interpreting technological innovation data. Paris: OECD: Statistical Office of the European Communities, 1997)

Marins, L. M. (2010) Atividade de inovação em firmas de economias emergentes: proposta de um conjunto de novos indicadores. Tese de Doutorado apresentada à Universidade Federal do Rio Grande do Sul, Escola de Administração, Programa de Pós-Graduação em Administração. Porto Alegre.

Matesco, V. R. (1993) Inovação Tecnológica das Empresas Brasileiras: a diferenciação competitiva e a motivação para inovar. $384 \mathrm{f}$. Tese de Doutorado em Economia Industrial apresentada à Universidade Federal do Rio de Janeiro, Rio de Janeiro.

Miranda, E. S. L. (Coord.). Panorama 2003. Recuperado de http://www.anprotec.org.br

Pinto, J. S. (2004) Estudo da Mensuração do Processo de Inovação nas Empresas. 136f. Dissertação (mestrado) - Universidade Estadual de Campinas, Faculdade de Engenharia Mecânica. Campinas, SP.

RMI - Rede Mineira de Inovação. Retirado de http://www.rmi.org.br

Schumpeter, J. A. (1982) A Teoria do Desenvolvimento Econômico: uma investigação sobre lucros, capital, crédito, juro e o ciclo econômico. 3 ed. São Paulo: Abril Cultural. 340 p.

Sink, D. S., \& Tuttle, T. C. (1993) Planejamento e Medição para a Performance. Rio de Janeiro: Qualitymark. $331 \mathrm{p}$.

Tushman, M., \& Nadler, D. (1986) Organizing for Innovation. California Management Review, v. XXVIII, n. 3, Spring, p. 74-92.

Vantrappen, H. F., \& Metz, P. D. (1995) Medindo o desempenho do processo de inovação. Revista de Administração de Empresa, São Paulo, v.35, n.3, p. 80-87.

Viotti, E. B. (2003) Fundamentos e Evolução dos Indicadores de CT\&I. In: VIOTTI, Eduardo Baumgratz; MACEDO, Mariano de Matos (Orgs.). Indicadores de Ciência, Tecnologia e Inovação no Brasil. Campinas, SP: Editora da UNICAMP. cap. 1, p. 41-87.

Vohora, A., Wright, M., \& Lockett, A. (2004) Critical junctures in the development of university hightech spinout companies. Research Policy, Nottingham, v.33, p. 147-175. 


\title{
INNOVATION MEASUREMENT BASED BUSINESS TECHNOLOGY
}

\begin{abstract}
Innovation has been used for an increasing number of companies as a strategy to gain competitive advantage. To foster the development of innovation, many governments have encouraged the development of business incubators. Among the types of incubators, stand out in the context of innovation, the technology-based ones which are those that work with companies that have great potential for innovation. Despite the importance of innovation in today's context, particularly related to the technology-based companies, there was no consensus in the literature regarding a set of indicators to monitor the innovation process. Knowing this context, the objective of this research is to analyse the mechanisms used to measure the technology innovation process and to propose a set of indicators to monitor this process in technology-based enterprises. To this end, an exploratory study of business incubators associated with Rede Mineira de Inovação (RMI) and of some of their incubated companies, has been done, through structured questionnaires and semi structured interviews. The research investigated the use of mechanisms to measure the innovation in technology based enterprises and verified this is an unknown issue for the majority of the respondents. Based on the problems and needs pointed out and the innovation indicators found in the studied literature, a set of innovation indicators related to control of the innovation process for these companies was proposed.
\end{abstract}

Key words: Business Incubators; Technology Based Companies; Innovation Indicators.

Data do recebimento do artigo: 14/08/2015

Data do aceite de publicação: 10/12/2015

Revista de Administração e Inovação, São Paulo, v. 12, n.4 p. 232-253, out./dez. 2015. 